\title{
A BDNF Coding Variant is Associated with the NEO Personality Inventory Domain Neuroticism, a Risk Factor for Depression
}

\author{
Srijan Sen', Randolph M. Nesse, ${ }^{2,3}$, Scott F. Stoltenberg, ${ }^{2,4}$, Sheng Li $^{5}$, Lillian Gleiberman ${ }^{6}$, Aravinda \\ Chakravarti $^{8}$, Alan B. Weder ${ }^{6}$ and Margit Burmeister*, ${ }^{*, 2,5,7}$ \\ 'Neuroscience Program, University of Michigan, Ann Arbor, MI, USA; ²Department of Psychiatry, University of Michigan, Ann Arbor, MI, USA; \\ ${ }^{3}$ Department of Psychology, Institute for Social Research, University of Michigan, Ann Arbor, MI, USA; ${ }^{4}$ Addiction Research Center, University of \\ Michigan, Ann Arbor, MI, USA; ${ }^{5}$ Mental Health Research Institute, University of Michigan, Ann Arbor, MI, USA; ${ }^{6}$ Department of Internal Medicine, \\ University of Michigan, Ann Arbor, MI 48105, USA; ${ }^{7}$ Department of Human Genetics, University of Michigan, Ann Arbor, MI, USA; ${ }^{8}$ McKusick- \\ Nathans Institute of Genetic Medicine, School of Medicine, Johns Hopkins University, Baltimore, MD, USA \\ Neuropsychopharmacology (2003) 28, 397-40I. doi:I 0.1 038/s..npp. I 300053
}

Keywords: neurotrophin; NEO-PI; personality; polymorphism; anxiety; neurogenesis

\section{INTRODUCTION}

Genetic factors influence vulnerability to depression (Sullivan et al, 2000), but no specific genes have been definitively implicated. One promising approach is to determine whether variations in specific (candidate) genes are associated not with disease per se, but with traits, such as personality factors, that are themselves associated with risk for the disorder (Lander and Schork, 1994; Stoltenberg and Burmeister, 2000). Often such traits have a higher heritability than the disease status (Almasy and Blangero, 2001). Neuroticism, as measured by the NEO personality inventory (NEO-PI) (Costa and McCrae, 1997), a psychometrically sound and widely used instrument, is one such trait. High scorers on the Neuroticism domain are characterized by frequent experience of 'negative emotionality' such as anxiety, low mood, and hostility. Converging lines of evidence point to brain-derived neurotrophic factor (BDNF) as a factor in the pathophysiology of depression. To explore the possibility that variation in the BDNF gene is, in part, responsible for the population variation in Neuroticism, we studied a community sample of 441 subjects, genotyping a $\mathrm{G} \rightarrow \mathrm{A}$ single-nucleotide polymorphism (SNP) responsible for a valine $\rightarrow$ methionine substitution in the prodomain of BDNF. The less common, nonconserved Met

\footnotetext{
*Correspondence: Dr M Burmeister, Mental Health Research Institute, University of Michigan, 205 Zina Pitcher Place, Ann Arbor, MI 48I09-0720, USA, Tel: + I 734647 2186, Fax: + I 734647 4I30, E-mail: margit@umich.edu

Received 22 March 2002; revised 19 June 2002; accepted 21 August 2002

Online publication: 29 August 2002 at http://www.acnp.org/citations/ Npp082902374
}

allele was associated with significantly lower mean Neuroticism scores $(p=0.0057)$. Our study provides further evidence and one possible mechanism linking BDNF to depression.

BDNF influences neuronal differentiation in development, as well as synaptic plasticity and neuronal survival in adulthood (Thoenen, 1995). Several results suggest that it may play a role in the pathophysiology of depression (Duman, 2002). Heterozygous BDNF knockout mice show behavioral abnormalities consistent with serotonergic dysfunction. These behavioral changes are corrected through antidepressant treatment (Lyons et al, 1999). Additional evidence connecting BDNF and depression comes from studies showing that infusion of recombinant BDNF into the mouse midbrain (Siuciak et al, 1997) or hippocampus (Duman, 2002) produces an antidepressant effect in both learned helplessness and forced swim models of depression. Furthermore, stress, a trigger for depression, lowers hippocampal transcription of BDNF in mice (Nibuya et al, 1995). In contrast, numerous antidepressants, including selective serotonin reuptake inhibitors, electroconvulsive therapy, lithium, and monoamine oxidase inhibitors (Nibuya et al, 1995; Russo-Neustadt et al, 1999), increase BDNF transcription. This transcriptional increase occurs after a delay similar to that seen in the onset of clinical effects of antidepressants (Nibuya et al, 1995).

The recent finding that there is significant neurogenesis in the hippocampi of adult primates suggests a mechanism through which BDNF might relate to depression (Gould et al, 1999). The hippocampi of depressed patients are significantly smaller than those of healthy individuals (Sheline, 2000). This reduced volume may be the result of decreased neurogenesis in depressed individuals, a possi- 
bility supported by the findings that hippocampal neurogenesis is reduced by stress (Gould et al, 1998) and increased by antidepressant treatment (Malberg et al, 2000). The parallel changes in BDNF levels and neurogenesis in response to stress and antidepressant treatment suggest a connection between BDNF and hippocampal neurogenesis. Together, these lines of evidence lead to the neurotrophic hypothesis of depression (Duman et al, 1997), suggesting that genetic variations in BDNF might influence hippocampal neurogenesis and ultimately vulnerability to depression.

Neuroticism is a strong marker for vulnerability to depression (Duggan et al, 1995; Kendler et al, 1993). Characteristics of Neuroticism make it particularly useful for genetic studies of depression. The reported heritability of Neuroticism is $40-50 \%$ (Jang et al, 1996; Lake et al, 2000), equal to or greater than heritibility estimates for depression (36\%) (Kendler and Prescott, 1999). Furthermore, approximately $70 \%$ of the correlation between Neuroticism and depression risk is because of shared genetic risk factors (Kendler et al, 1993). Neuroticism is also a quantitative trait and stable through adulthood (Costa and McCrae, 1988). In this study, we explore whether a BDNF variant is associated with variation in Neuroticism.

\section{METHODS}

\section{Subjects}

The subjects, 268 female and 173 male, were from 257 families participating in the Family Blood Pressure Program at the Tecumseh, Michigan Site (Boerwinkle, 2002). In all, $99 \%$ of the subjects were non-Hispanic Caucasians. Family eligibility in this study was dependent on the availability of a proband between 25 and 40 years old with a systolic blood pressure in the upper $15 \%$ of blood pressure distribution in earlier rounds of examination. Parents and siblings of probands were studied when available.

\section{Genotyping}

In Genbank sequences and the public SNP database (http:// www.ncbi.nlm.nih.gov/), we identified a common coding variant in the $B D N F$ gene, a $\mathrm{G} \rightarrow \mathrm{A}$ polymorphism responsible for a Val66Met change (Cargill et al, 1999). Electronic restriction mapping showed that the 'A' allele creates a restriction site for the enzyme Hsp92II. We designed primers (SBDNF1-AAA GAA GCA AAC ATC CGA GGA CAA G; SBDNF2-ATT CCT CCA GCA GAA AGA GAA GAG $\mathrm{G})$ resulting in a $274 \mathrm{bp}$ PCR product. A PTC 100 thermal cycler (MJ Research, Watertown, MA, USA) was used for DNA amplification. Amplification reactions were performed in a total volume of $20 \mu \mathrm{l}$, containing approximately $50 \mathrm{ng}$ of genomic template, $1 \mu \mathrm{M}$ of each primer, $200 \mu \mathrm{M}$ dNTP, $2 \mu \mathrm{l}$ 10X Opti-Prime Buffer 6 (Stratagene, La Jolla, CA, USA) and $1 \mathrm{U}$ of Taq polymerase. The PCR cycling conditions consisted of an initial denaturation for $2 \mathrm{~min}$ at $94^{\circ} \mathrm{C}$ followed by 35 cycles of $94^{\circ} \mathrm{C}$ for $1 \mathrm{~min}, 55^{\circ} \mathrm{C}$ for $2 \mathrm{~min}$, and 72 for $2 \mathrm{~min}$ and a final extension at $72^{\circ} \mathrm{C}$ for $4 \mathrm{~min}$. In the presence of the ' $\mathrm{G}$ ' allele, Hsp92II digestion produced two products, 57 and $217 \mathrm{bp}$, whereas the 'A' allele produced 3 products, 57, 77, and $140 \mathrm{bp}$. The presence of a second
Hsp92II site served as a restriction digest control, identifying incomplete digests for repeat analysis. PCR products were electrophoresed on a $2 \%$ agarose gel and visualized using the Gel-Star nucleic acid gel stain (BioWhittaker Molecular Applications, Rockland, ME, USA). Of all subjects, $91 \%$ were successfully genotyped.

\section{Personality Inventory}

The NEO-PI was administered to the subjects in the study. This inventory, consisting of 181 questions, assesses subjects on five global personality domains and breaks down three of these domains into six specific facets each. The NEO-PI is a well-established inventory designed through factor analytic strategies. The inventory provides high test-retest reliability and longitudinal stability (Costa and McCrae, 1997).

\section{Statistical Analysis}

The presence of association was determined using the QTDT Program version 2.1 (available at http://www.sph. umich.edu/statgen/abecasis/QTDT/). QTDT was used to fit a variance components model to account for familial resemblance because of kinship and linkage. However, rather than modeling allelic effects based on allelic transmission, we tested the overall additive genetic effect of each polymorphism (Abecasis et al, 2000a, b).

\section{RESULTS}

We analyzed DNA samples from 441 subjects in the Tecumseh, Michigan Blood Pressure Study (Boerwinkle, 2002) at a $\mathrm{G} \rightarrow$ A polymorphism responsible for a Val66Met change (Cargill et al, 1999) in the prodomain of the BDNF gene. The frequency of the alleles (adjusted for familial correlations) were: $\mathrm{Val}=0.75$, Met $=0.25$, similar to previously reported frequencies $(\mathrm{Val}=0.68$ and 0.83 , Met $=0.32$ and 0.17) (Cargill et al, 1999; Sklar, in press). In this sample there was no significant correlation between blood pressure and Neuroticism (diastolic blood pressure $r=-0.064, p=0.116$; systolic blood pressure $r=-0.016$, $p=0.696)$. Since the mean Neuroticism score for the heterozygous Val/Met group was intermediate to the two homozygous groups, an additive model of genotype effect was used. In an analysis controlling for familial correlations, the Met allele showed a significant association with lower mean Neuroticism scores $(p=0.0057$; Figure 1$)$. No personality domain, other than Neuroticism, was associated with BDNF genotype (Table 1). Of the six Neuroticism facets, only depression (N3), self-consciousness (N4), anxiety (N1), and vulnerability (N6) were associated with $\mathrm{BDNF}$ genotype. Of the 12 facets comprising the other personality domains, only the openness facet, feelings (O3) was associated with BDNF genotype (Table 2). This association was modest. For all but one of the associated facets, the heterozygous Val/Met group score was intermediate to the two homozygous groups, supporting an additive model for genotype effect. For the $\mathrm{O} 3$ facet, the heterozygous $\mathrm{Val} / \mathrm{Met}$ group score was similar to the Met/ Met group score, supporting a model where the Met allele may have a dominant effect. 


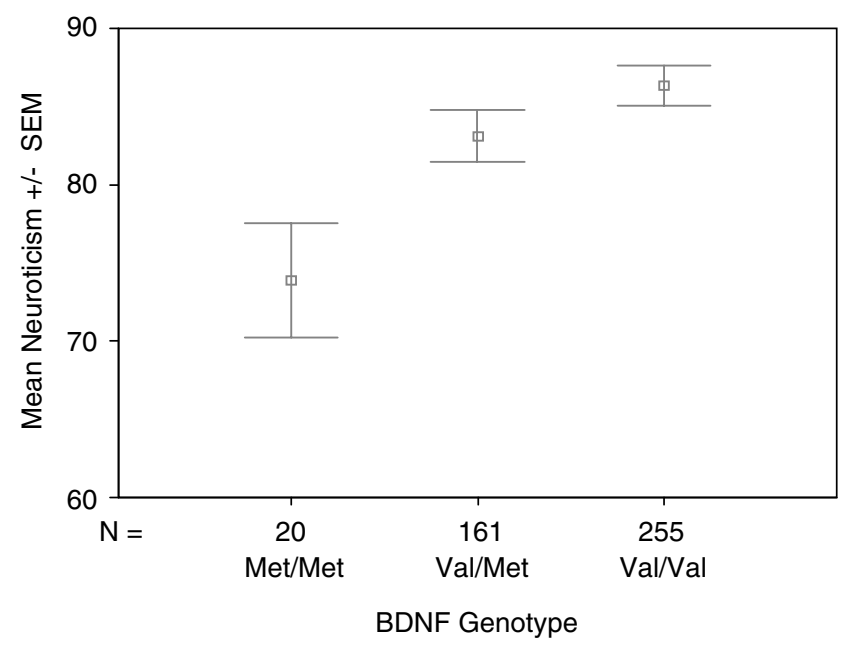

Figure I NEO-PI neuroticism scores as a function of BDNF genotype.

Table I NEO-PI domain scores as a function of BDNF genotype

\begin{tabular}{llcccc}
\hline \multirow{2}{*}{ Domain } & BDNF & & & & \\
& genotype & N & Mean & SEM & p value \\
\hline Neuroticism & Val/Nal & 255 & 86.35 & 1.27 & 0.0057 \\
& Val/Met & 161 & 83.11 & 1.67 & \\
& Met/Met & 20 & 73.90 & 3.66 & \\
Extraversion & & & & & \\
& Val/Val & 255 & 107.22 & 1.07 & 0.329 \\
& Val/Met & 162 & 108.17 & 1.40 & \\
& Met/Met & 20 & 111.18 & 2.76 & \\
Openness & & & & & \\
& Val/Val & 254 & 104.19 & 1.07 & 0.197 \\
& Val/Met & 160 & 101.90 & 1.23 & \\
Conscientiousness & Met/Met & 20 & 102.18 & 3.69 & \\
& Val/Val & 258 & 48.10 & 0.50 & 0.736 \\
& Val/Met & 161 & 47.53 & 0.66 & \\
& Met/Met & 20 & 48.53 & 1.95 & \\
Agreeableness & Val/Val & 259 & 47.19 & 0.40 & 0.721 \\
& Val/Met & 162 & 47.21 & 0.55 & \\
& Met/Met & 20 & 48.05 & 1.94 & \\
\hline
\end{tabular}

A concern for this type of study is the potential presence of population stratification resulting in the appearance of false associations (Lander and Schork, 1994). To assess if the reported results were because of stratification, STRUCTURE, a program designed to infer population structure utilizing genotypes from numerous unlinked markers as genomic controls, was implemented (Pritchard and Rosenberg, 1999). Weak evidence for clustering into two groups was found $(p=0.02)$ (Theil and Schork, personal communication; data available upon request). There were no significant differences in either BDNF allele frequency or any of the personality traits between the two clusters. Furthermore, the population cluster that was nonsignificantly higher for mean Neuroticism scores had a nonsignificantly greater Met allele frequency. Thus, these reported results are unlikely to be the product of population stratification (data available on request). An additional concern for this study is that the population sample studied
Table 2 NEO-PI facet scores ${ }^{a}$ as a function of BDNF genotype in Tecumseh population

\begin{tabular}{|c|c|c|c|c|c|}
\hline Facet & $\begin{array}{l}\text { BDNF } \\
\text { genotype }\end{array}$ & $\mathbf{N}$ & Mean & SEM & $p$ value \\
\hline NI - anxiety & $\begin{array}{l}\text { Val/Nal } \\
\text { Val/Met } \\
\text { Met/Met }\end{array}$ & $\begin{array}{r}258 \\
161 \\
20\end{array}$ & $\begin{array}{l}\mid 5.83 \\
\mid 4.94 \\
13.52\end{array}$ & $\begin{array}{l}0.31 \\
0.38 \\
1.02\end{array}$ & 0.0020 \\
\hline N2-hostility & $\begin{array}{l}\text { Val/Nal } \\
\text { Val/Met } \\
\text { Met/Met }\end{array}$ & $\begin{array}{r}258 \\
161 \\
20\end{array}$ & $\begin{array}{l}12.18 \\
11.98 \\
11.77\end{array}$ & $\begin{array}{l}0.28 \\
0.37 \\
0.82\end{array}$ & 0.597 \\
\hline N3-depression & $\begin{array}{l}\text { Val/Nal } \\
\text { Val/Met } \\
\text { Met/Met }\end{array}$ & $\begin{array}{r}255 \\
161 \\
20\end{array}$ & $\begin{array}{l}14.39 \\
13.34 \\
11.39\end{array}$ & $\begin{array}{l}0.34 \\
0.46 \\
1.04\end{array}$ & 0.0058 \\
\hline N4 — self-consciousness & $\begin{array}{l}\text { Val/Nal } \\
\text { Val/Met } \\
\text { Met/Met }\end{array}$ & $\begin{array}{r}258 \\
161 \\
20\end{array}$ & $\begin{array}{l}\mid 5.74 \\
\mid 4.86 \\
13.05\end{array}$ & $\begin{array}{l}15.74 \\
\mid 4.86 \\
\mid 3.05\end{array}$ & 0.0086 \\
\hline N5 —impulsiveness & $\begin{array}{l}\text { Val/Nal } \\
\text { Val/Met } \\
\text { Met/Met }\end{array}$ & $\begin{array}{r}258 \\
161 \\
20\end{array}$ & $\begin{array}{l}16.72 \\
16.9 \mid \\
15.15\end{array}$ & $\begin{array}{l}0.23 \\
0.31 \\
1.13\end{array}$ & 0.497 \\
\hline N6 - vulnerability & $\begin{array}{l}\text { Val/Nal } \\
\text { Val/Met } \\
\text { Met/Met }\end{array}$ & $\begin{array}{r}259 \\
162 \\
20\end{array}$ & $\begin{array}{r}|1.4| \\
\mid 1.08 \\
9.00\end{array}$ & $\begin{array}{l}0.23 \\
0.34 \\
0.70\end{array}$ & 0.0390 \\
\hline O3-feelings & $\begin{array}{l}\text { Val/Nal } \\
\text { Val/Met } \\
\text { Met/Met }\end{array}$ & $\begin{array}{r}254 \\
161 \\
20\end{array}$ & $\begin{array}{l}20.90 \\
19.78 \\
19.92\end{array}$ & $\begin{array}{l}0.24 \\
0.28 \\
0.83\end{array}$ & 0.0215 \\
\hline
\end{tabular}

${ }^{a}$ All six Neuroticism facets are shown along with $\mathrm{O}$, the only facet from the other domains that reached nominal significance.

was chosen through the presence of a moderately hypertensive proband. Although there is no association in this sample between blood pressure and either BDNF or Neuroticism, the hypertensive nature of the sample should be noted. Lastly, we have demonstrated a role for this BDNF variant in personality variation in a rural Michigan, nonHispanic Caucasian sample, but its role in other populations is not known.

\section{DISCUSSION}

Our results indicate that this BDNF polymorphism may account for a small, but significant proportion of the population variation in Neuroticism. This variant explains about $4 \%$ of the genetic variance in our sample. There are several reasons to think that these results for Neuroticism are relevant to depression. First, Neuroticism is strongly associated with depression (Duggan et al, 1995; Kendler et $a l, 1993)$. This established association between Neuroticism and depression is mediated entirely by four of the six Neuroticism facets: anxiety (N1), depression (N3), selfconsciousness (N4), and vulnerability (N6) (Bagby et al, 1996). These four facets are precisely those that associate with BDNF genotype in the Tecumseh sample. The other two Neuroticism facets, hostility (N2) and impulsiveness (N5), are not associated with depression and show no association with BDNF in this study (Table 2). Outside of the Neuroticism domain, the facets that have been 
associated with depression are aesthetics (O2) and feelings (O3) (Bagby et al, 1996; Wolfenstein and Trull, 1997). In our sample, the feelings (O3) facet is significantly associated with BDNF while aesthetics (O2) shows a trend towards an association $(p<0.10)$. The reported $p$ values were not corrected for multiple testing. However, when the BDNF association with Neuroticism is corrected for the 5 NEO-PI domains, the results remain significant. This is conservative since we went into this study with an a priori hypothesis that BDNF may be a candidate gene for Neuroticism, not the other domains. Since the facets are strongly associated with each other, it is difficult to assess how to correct for further multiple testing.

Further evidence that the Val allele might increase the risk of depression comes from a study showing that this Val allele was preferentially transmitted to bipolar probands in families (Sklar, in press). The finding that the Val allele is associated with the risk of clinical bipolar disorder supports our findings that the same allele is associated with increased scores on personality facets associated with depression in a community sample. While the effect size of this BDNF variant for Neuroticism is not large, the effect is in the same direction as in bipolar disorder and of the magnitude expected for an intermediate phenotype in a polygenic trait.

The functional significance of this $\mathrm{Val} \rightarrow$ Met substitution, if any, is unknown. Protein sequence comparisons (data not shown) reveal that the common Val allele is completely conserved among $>70$ species including mammals, birds and fish (Murphy et al, 2001). That is, the 'protective' Met allele appears to be novel in evolutionary history. Our results, together with the neurotrophic hypothesis of depression (Duman et al, 1997), predict that the Met allele of BDNF produces higher activity or more efficient processing of BDNF. Given the proximity of this variant to a BDNF cleavage site, it is possible that this variant affects the efficiency of cleavage at this site (Mowla et al, 2001). The variant may also be involved in determining the efficiency of mature BDNF folding. Alternatively, the variant may have no functional consequence, but be in linkage disequilibrium with a nearby functional polymorphism. These models can be tested in vitro or in animal models. Given the increase of BDNF transcription in response to antidepressant treatment, further work is also indicated to determine if this genetic variation predicts clinical response to specific antidepressants.

\section{ACKNOWLEDGMENTS}

We thank all the families who participated in the studies, Goncalo Abecasis, Bonnie Theil, Nicholas Schork, Maria Carolina Delgado, Miriam Meisler and Julie Douglas for helpful discussions, and Aashish Didwania and Grace Wang for data management assistance. This work was supported by the Nancy Pritzker Depression Research Network (RMN, $\mathrm{MB})$, the University of Michigan MSTP training Grant GM007863 (SS), NIAAA Grants AA07065 (RAZ, HEF), AA00295 (SFS), a Biomedical Research Grant from Michigan State University, and pilot fund support from the University of Michigan Addiction Research Center. Recruitment and DNA acquisition for the Tecumseh study was funded by NHLBI Grant HL054512 (LG, AW, and AC).

\section{REFERENCES}

Abecasis GR, Cardon LR, Cookson WO (2000a). A general test of association for quantitative traits in nuclear families. Am J Hum Genet 66: 279-292.

Abecasis GR, Cookson WO, Cardon LR (2000b). Pedigree tests of transmission disequilibrium. Eur J Hum Genet 8: 545-551.

Almasy A, Blangero J (2001). Endophenotypes as quantitative risk factors for psychiatric disease: rationale and study design. Am J Med Genet 105: 42-44.

Bagby RM, Young LT, Schuller DR et al (1996). Bipolar disorder, unipolar depression and the Five-Factor Model of personality. $J$ Affect Disord 41: 25-32.

Boerwinkle E, Brown CA, Carrejo M, Ferrell R, Hanis C, Hutchinson $\mathrm{R}$ et al (2002). Multi-center genetic study of hypertension-The Family Blood Pressure Program (FBPP). Hypertension 39: 3-9.

Cargill M, Altshuler D, Ireland J, Sklar P, Ardlie K, Patil N et al (1999). Characterization of single-nucleotide polymorphisms in coding regions of human genes. Nat Genet 22: 231-238.

Costa Jr PT, McCrae RR (1988). Personality in adulthood: a six-year longitudinal study of self-reports and spouse ratings on the NEO personality inventory. J Pers Soc Psychol 54: 853-863.

Costa Jr PT, McCrae RR (1997). Stability and change in personality assessment: the revised NEO personality inventory in the year 2000. J Pers Assess 68: 86-94.

Duggan C, Sham P, Lee A, Minne C, Murray R (1995). Neuroticism: a vulnerability marker for depression evidence from a family study. J Affect Disord 35: 139-143.

Duman RS (2002). Synaptic plasticity and mood disorders. Mol Psychiatry 7: S29-34.

Duman RS, Heninger GR, Nestler EJ (1997). A molecular and cellular theory of depression [see comments]. Arch Gen Psychiatry 54: 597-606.

Gould E, Reeves AJ, Graziano MS, Gross CG (1999). Neurogenesis in the neocortex of adult primates [see comments]. Science 286: 548-552.

Gould E, Tanapat P, McEwen BS, Flugge G, Fuchs E (1998). Proliferation of granule cell precursors in the dentate gyrus of adult monkeys is diminished by stress. Proc Natl Acad Sci USA 95: $3168-3171$.

Jang KL, Livesley WJ, Vernon PA (1996). Heritability of the big five personality dimensions and their facets: a twin study. J Pers 64: 577-591.

Kendler KS, Neale MC, Kessler RC, Heath AC, Eaves LJ (1993). A longitudinal twin study of personality and major depression in women. Arch Gen Psychiatry 50: 853-862.

Kendler KS, Prescott CA (1999). A population-based twin study of lifetime major depression in men and women. Arch Gen Psychiatry 56: 39-44.

Lake RI, Eaves LJ, Maes HH, Heath AC, Martin NG (2000). Further evidence against the environmental transmission of individual differences in neuroticism from a collaborative study of 45,850 twins and relatives on two continents. Behav Genet 30: 223-233.

Lander ES, Schork NJ (1994). Genetic dissection of complex traits. Science 265: 2037-2048.

Lyons WE, Mamounas LA, Ricaurte GA et al (1999). Brain-derived neurotrophic factor-deficient mice develop aggressiveness and hyperphagia in conjunction with brain serotonergic abnormalities. Proc Natl Acad Sci USA 96: 15239-15244.

Malberg JE, Eisch AJ, Nestler EJ, Duman RS (2000). Chronic antidepressant treatment increases neurogenesis in adult rat hippocampus. J Neurosci 20: 9104-9110.

Mowla SJ, Farhadi HF, Pareek S et al (2001). Biosynthesis and posttranslational processing of the precursor to brain-derived neurotrophic factor. J Biol Chem 276: 12660-12666. 
Murphy WJ, Eizirik E, Johnson WE, Zhang YP, Ryder OA, O’Brien SJ (2001). Molecular phylogenetics and the origins of placental mammals. Nature 409: 614-618.

Nibuya M, Morinobu S, Duman RS (1995). Regulation of BDNF and trkB mRNA in rat brain by chronic electroconvulsive seizure and antidepressant drug treatments. J Neurosci 15: 75397547.

Pritchard JK, Rosenberg NA (1999). Use of unlinked genetic markers to detect population stratification in association studies. Am J Hum Genet 65: 220-228.

Russo-Neustadt A, Beard RC, Cotman CW (1999). Exercise, antidepressant medications, and enhanced brain derived neurotrophic factor expression. Neuropsychopharmacology 21: 679682.

Sheline YI (2000). 3D MRI studies of neuroanatomic changes in unipolar major depression: the role of stress and medical comorbidity. Biol Psychiatry 48: 791-800.
Siuciak JA, Lewis DR, Wiegand SJ, Lindsay RM (1997). Antidepressant-like effect of brain-derived neurotrophic factor (BDNF). Pharmacol Biochem Behav 56: 131-137.

Sklar P, Bolk S, McInnis MG, Bennett P, Lim Y-M, Tsan G et al (in press). Family based association study identifies BDNF as a potential risk locus for bipolar disorder. Mol Psychiatry 7: 579593.

Stoltenberg SF, Burmeister M (2000). Recent progress in psychiatric genetics-some hope but no hype. Hum Mol Genet 9: 927935.

Sullivan PF, Neale MC, Kendler KS (2000). Genetic epidemiology of major depression: review and meta-analysis. Am J Psychiatry 157: 1552-1562.

Thoenen H (1995). Neurotrophins and neuronal plasticity. Science 270: $593-598$.

Wolfenstein M, Trull TJ (1997). Depression and openness to experience. J Pers Assess 69: 614-632. 